\title{
Identification of Rice Hybrids and Restorer Line Using Microsatellite Markers
}

\author{
Alice Xalxo, Prabha R. Chaudhari*, Deepak Sharma, Ritu R. Saxena, \\ Satyapal Singh and AashishTiwari
}

Department of Genetics and Plant breeding, College of Agriculture Raipur, IGKV, (C.G.), India

*Corresponding author

\author{
A B S T R A C T
}

Twenty four hybrids developed from three CMS lines viz. IR79156A, CRMS 31A and CRMS 32A and eight diverse rice genotypes were included in the present study. Molecular

\section{Keywords}

Rice, Identification Restorers, Molecular Marker, Rf4.

\section{Article Info}

Accepted:

26 September 2017

Available Online:

10 November 2017 marker assisted identification with high power of genetic resolutions has emerged as a robust technique for cultivar fingerprinting, identity profiling, estimating and comparing genetic similarity, and variety protection. Out of sixteen, ten SSR markers produced polymorphic bands in the rice genotypes.RM171 and RM 216 were successfully recognized as hybrid and was discriminated from its parental lines (with same alleles).PCR based markers RM171 linked to Rf4 respectively, found to be more accurate compared to other linked markers in identifying restorers and differentiating maintainers from others. Molecular screening with RM171 for fertility restoration can be a useful tool for identifying restorers from breeding lines of unknown restoration status with $100 \%$ efficiency without making and evaluating large number of test crosses. These markers are useful in marker assisted identification of $R f$ genes in back cross breeding program to develop near isogenic lines with multiple $R f$ genes towards the development of superior restorer lines.

\section{Introduction}

Rice yields have been reported to be stagnant due to genetic ceiling and it is opposite to human population which increases steadily. Alternative technologies are needed to overcome barriers to increase rice productivity viz. new plant type, hybrid rice and molecular breeding. Among these hybrid rice technology is an important approach for improving rice production. Whereas the first progeny will perform better than their parent lines. Hybrid rice known having 15-25\% higher yield advantage than inbreed rice. This technology is not contributing to food security but also beneficial to the environment.
The fingerprinting of rice hybrids and identification of their genetic relationships are very important for quality hybrid seed and plant yield improvement. Accordingly, clearcut identification of elite crop varieties and hybrids is essential for protection and prevention of unauthorized commercial use (Nandakumr et al., 2004). In rice, it was reported that $1 \%$ impurity in hybrid seeds caused the yield reduction of $100 \mathrm{~kg}$ per hectare, hence, determination of seed genetic purity in hybrid crops is crucial to confirm the hybridization and resulted increased grain yields through heterosis. 
Conventional characterization of hybrids based on specific morphological and agronomic data is time-consuming, restricted to a few characteristics, influenced by environmental condition and are inefficient. Molecular marker assisted identification with high power of genetic resolutions has emerged as a robust technique for cultivar fingerprinting, identity profiling, estimating and comparing genetic similarity, and variety protection.

SSR has much more polymorphism than most of other DNA markers, and is co-dominant and large in quantity. Therefore, SSR has become an ideal molecular marker for identification of plant variety and for genetic purity testing of hybrids

In hybrid rice technology maintainer and restorer lines will be identified by crossing parental (testers) lines with a CMS line and evaluating the $F_{1}$ for pollen and spikelet fertility. This system of restorer identification is time consuming and labour intensive. CMS line can be restored by nuclear genes governing fertility restoration ( $R f$ genes) (Nematzadeh and Kiani, 2010). Among five fertility restorer genes identified for WA (wild abortive) cytoplasm. Among theseRf3 and Rf4 genes reported to be of more value for identification of restorers (Revathi et al., 2013). Several DNA markers closely linked to $R f$ genes have been reported (Ahmadakhah $e t$ al., 2007, Bazrkar et al., 2008, Alavi et al., 2009, Neeraja et al., 2009, Sheeba et al., 2009 and Grishma Shah et al., 2012) which are useful in marker assisted identification of restorers in rice germplasm and further use in hybrid breeding program. This information in normal breeding the reported markers need to be validated. In order to utilize present study was undertaken to DNA profiling of hybrids rice, their parental lines and to screen of restorer line markers linked with fertility restoration.

\section{Materials and Methods}

The present investigation was conducted at Research cum Instructional farm and molecular biology laboratory of department of Genetics and Plant breeding, College of Agriculture, IGKV Raipur during Kharif, 2014.

\section{Plant Material and Genomic DNA isolation}

The experimental materials for the present investigation comprises of three CMS lines and eight testers. Total 24 hybrids were developed in line X tester fashion. Out of 24 hybrids, eight hybrids were included in the study. Details of these lines are presented in the Table 1.

Total rice genomic DNA extracted from young succulent, disease and insect free seedlings by mini prep method. Genomic DNA was isolated from young leaves of 10 plants of each parent lines while the leaves of individual plant were used for hybrids. DNA was extracted to given by Doyle and Doyle, 1987 procedure with minor modification.

The extracted DNA content was quantified and parental polymorphism studies done through 16 SSRs primers. PCR mix for one reaction (volume $20 \mu \mathrm{l}$ ) contained $2 \mu \mathrm{l}$ DNA, Sterile and Nanopure water $13.5 \mu 1,10 \mathrm{x}$ Assay buffer, $1 \mu 1 \mathrm{dNTP}, 0.5 \mathrm{ul}$ of each forward and reverse primer, 0.5 ulTaq DNA polymerase.

PCR Amplification was performed with the following steps: predenaturing at $94^{\circ} \mathrm{C}$ for 4 min, followed by 35 cycles of $94^{\circ} \mathrm{C}$ for $1 \mathrm{~min}$, $55^{\circ} \mathrm{C}$ for $1 \mathrm{~min}$, and $72^{\circ} \mathrm{C}$ for $2 \mathrm{~min}$, and last step is $5 \mathrm{~min}$ at $72^{\circ} \mathrm{C}$

Amplified products were analyzed using 5\% polyacrylamide gel. Electrophores is done for $1 \mathrm{hr}$ at 199 volts. The gel along with the DNA 
sample then stained with Eithidium bromide (10 $\mu \mathrm{g} / 10 \mathrm{ml}$ ) for 40-45 mins. Gel was visualized on UV- transilluminator and image can be seen in computer.

\section{SSR assay}

PCR analysis was done using a set of 16 SSR (simple sequence repeat) markers (Table 2) to identify the parental polymorphism between three lines (IR 79156A, CRMS31A and CRMS 32A and eight testers viz., Jawaphool, Swarna sub 1, R-1656-2816-9-2-3223-1, NPT-1, NPT-2, NPT-4, NPT-17, NPT-38. The genotypic dataset was generated based on the PCR amplification

Profile by scoring presence and absence of specific allele with specific base pair (bp) size for all the samples. Validation of linked markers was carried out using for identified restorers.

\section{Results and Discussion}

Eight hybrids along with their respective parents were analyzed with ten most informative SSR markers and hybrids, those showing bands for both the parents (cytoplasmic male sterile lines and restorer lines) were identified as pure hybrid.

\section{Genetic purity testing}

Being co-dominant, polymorphic SSR markers were used to test the seed purity of rice hybrids. As expected, when polymorphic bands detected for two parent [CMS line (A) and restorer line $(\mathrm{R})]$, two alleles were observed in $F_{1}$ hybrid individuals, while off type seeds had only one allele. In this study, Seed purity test was carried out with individual seedlings in each hybrid by respected polymorphic markers.

Table.1 Rice hybrids and their parental lines used in this study

\begin{tabular}{|c|c|c|c|}
\hline S. No. & Hybrids / Parent lines & Type & Source \\
\hline 1 & IR 79156A (WA) & CMS & IRRI, Manila, Philippines \\
\hline 2 & CRMS 31A (Kalinga) & CMS & CRRI, Cuttack \\
\hline 3 & CRMS 32A (Kalinga) & CMS & CRRI, Cuttack \\
\hline 4 & Jawaphool & Tester & IGKV, Raipur, C.G. \\
\hline 5 & Swarna-sub-1 & Tester & CRRI, Cuttack \\
\hline 6 & R-1656-2816-9-3223-1 & Tester & IGKV, Raipur, C.G. \\
\hline 7 & NPT-1 & Tester & IGKV, Raipur C.G. \\
\hline 8 & NPT-2 & Tester & IGKV, Raipur C.G. \\
\hline 9 & NPT-17 & Tester & IGKV, Raipur C.G. \\
\hline 10 & NPT-38 & Tester & IGKV, Raipur C.G. \\
\hline 11 & Tester & IGKV, Raipur C.G. \\
\hline 12 & IR79156A / Swarna sub 1 & Hybrid & IGKV, Raipur C.G. \\
\hline 13 & IR79156A / NPT-38 & Hybrid & IGKV, Raipur C.G. \\
\hline 14 & CRMS31A / R-1656-2816-9- & Hybrid & IGKV, Raipur C.G. \\
\hline & 3223-1 & & \\
\hline 15 & CRMS31A / NPT-4 & Hybrid & IGKV, Raipur C.G. \\
\hline 16 & CRMS31A / NPT-17 & Hybrid & IGKV, Raipur C.G. \\
\hline 18 & CRMS32A / Jawaphool & Hybrid & IGKV, Raipur C.G. \\
\hline 19 & CRMS32A / NPT-1 & Hybrid & IGKV, Raipur C.G. \\
\hline & CRMS32A / NPT-2 & Hybrid & IGKV, Raipur C.G. \\
\hline
\end{tabular}


Table.2 List of SSR markers used to detect polymorphism among the parents (A and R lines)

\begin{tabular}{|c|c|c|c|c|c|}
\hline $\begin{array}{l}\text { S. } \\
\text { No. }\end{array}$ & Primer & $\begin{array}{l}\text { Forward/ } \\
\text { Reverse }\end{array}$ & $\begin{array}{l}\text { Sequence } \\
\text { 5,---------.-> 3, }\end{array}$ & $\begin{array}{l}\text { Polymorphic/ } \\
\text { Monomorphic }\end{array}$ & Position \\
\hline \multirow[t]{2}{*}{1} & RM-1 & Forward & GCGAAAACACAATGCAAAAA & Polymorphic & 1 \\
\hline & & Reverse & GCGTTGGTTGGACCTGAC & & \\
\hline \multirow[t]{2}{*}{2} & RM-154 & Forward & ACCCTCTCCGCCTCGCCTCCTC & Polymorphic & 2 \\
\hline & & Reverse & CTCCTCCTCCTGCGACCGCTCC & & \\
\hline \multirow[t]{2}{*}{3} & RM-263 & Forward & CCCAGGCTAGCTCATGAACC & Polymorphic & 2 \\
\hline & & Reverse & GCTACGTTTGAGCTACCACG & & \\
\hline \multirow[t]{2}{*}{4} & RM55 & Forward & CCGTCGCCGTAGTAGAGAAG & Monomorphic & 3 \\
\hline & & Reverse & TCCCGGTTATTTTAAGGCG & & \\
\hline \multirow[t]{2}{*}{5} & RM 514 & Forward & AGATTGATCTCCCATTCCCC & Monomorphic & 3 \\
\hline & & Reverse & CACGAGCATATTACTAGTGG & & \\
\hline \multirow[t]{2}{*}{6} & RM-168 & Forward & TGCTGCTTGCCTGCTTCCTTT & Polymorphic & 3 \\
\hline & & Reverse & GAAACGAATCAATCCACGGC & & \\
\hline \multirow[t]{2}{*}{7} & RM 307 & Forward & GTACTACCGACCTACCGTTCAC & Monomorphic & 4 \\
\hline & & Reverse & CTGCTATGCATGAACTGCTC & & \\
\hline \multirow[t]{2}{*}{8} & RM 124 & Forward & ATCGTCTGCGTTGCGGCTGCTG & Monomorphic & 4 \\
\hline & & Reverse & CATGGATCACCGAGCTCCCCCC & & \\
\hline \multirow[t]{2}{*}{9} & RM-164 & Forward & TCTTGCCCGTCACTGCAGATATCC & Polymorphic & 5 \\
\hline & & Reverse & GCAGCCCTAATGCTACAATTCTTC & & \\
\hline \multirow[t]{2}{*}{10} & RM 454 & Forward & CTCAAGCTTAGCTGCTGCTG & Monomorphic & 6 \\
\hline & & Reverse & GTGATCAGTGCACCATAGCG & & \\
\hline \multirow[t]{2}{*}{11} & RM 510 & Forward & AACCGGATTAGTTTCTCGCC & Monomorphic & 6 \\
\hline & & Reverse & TGAGGACGACGAGCAGATTC & & \\
\hline \multirow[t]{2}{*}{12} & RM-337 & Forward & GTAGGAAAGGAAGGGCAGAG & Polymorphic & 8 \\
\hline & & Reverse & CGATAGATAGCTAGATGTGGCC & & \\
\hline \multirow[t]{2}{*}{13} & RM-171 & Forward & AACGCGAGGACACGTACTTAC & Polymorphic & 10 \\
\hline & & Reverse & ACGAGATACGTACGCCTTTG & & \\
\hline \multirow[t]{2}{*}{14} & RM-216 & Forward & GCATGGCCGATGGTAAAG & Polymorphic & 10 \\
\hline & & Reverse & TGTATAAAACCACACGGCCA & & \\
\hline \multirow[t]{2}{*}{15} & RM-228 & Forward & CTGGCCATTAGTCCTTGG & Polymorphic & 10 \\
\hline & & Reverse & GCTTGCGGCTCTGCTTAC & & \\
\hline \multirow[t]{2}{*}{16} & RM-6100 & Forward & TCCTCTACCAGTACCGCACC & Polymorphic & 10 \\
\hline & & Reverse & GCTGGATCACAGATCATTGC & & \\
\hline
\end{tabular}

Table.3 Pollen fertility and spikelet fertility percentage of different CMS based hybrids in rice

\begin{tabular}{|c|c|c|c|c|c|c|c|}
\hline \multirow{2}{*}{ S.No. } & \multirow{2}{*}{ Genotypes } & \multicolumn{2}{|c|}{ IR-79156A } & \multicolumn{2}{c|}{ CRMS 31A } & \multicolumn{2}{c|}{ CRMS 32A } \\
\cline { 3 - 7 } & & SF \% & PF \% & SF \% & PF \% & SF \% & PF \% \\
\hline $\mathbf{1}$ & Jawaphool & 67.81 & 69.50 & 68.19 & 70.74 & 42.33 & 44.71 \\
\hline $\mathbf{2}$ & Swarna sub-1 & 76.54 & 78.54 & 63.66 & 64.92 & 72.51 & 74.7 .56 \\
\hline $\mathbf{3}$ & R-1656-2816-9-3223-1 & 61.61 & 62.67 & 78.28 & 62.67 & 67.88 & 70.60 .22 \\
\hline $\mathbf{4}$ & NPT-1 & 60.01 & 59.40 & 62.13 & 63.71 & 66.40 & 68.72 \\
\hline $\mathbf{5}$ & NPT-2 & 75.87 & 78.77 & 77.47 & 79.71 & 49.28 & 5434.01 \\
\hline $\mathbf{6}$ & NPT-4 & 77.47 & 80.07 & $\mathbf{7 9 . 3 2}$ & $\mathbf{8 1 . 3 2}$ & $\mathbf{7 7 . 1 5}$ & $\mathbf{8 2 . 5 1}$ \\
\hline $\mathbf{7}$ & NPT-17 & 50.12 & 53.66 & 77.11 & 79.73 & 52.67 & 50.59 \\
\hline $\mathbf{8}$ & NPT-38 & 73.24 & 75.77 & 76.60 & 78.46 & 68.85 & 70.53 \\
\hline
\end{tabular}

Note: (Pollen fertility \% >80 and spikelet fertility $\%>75$ ) Potential Restorer 
Table.4 Gel image label description of Fig.1

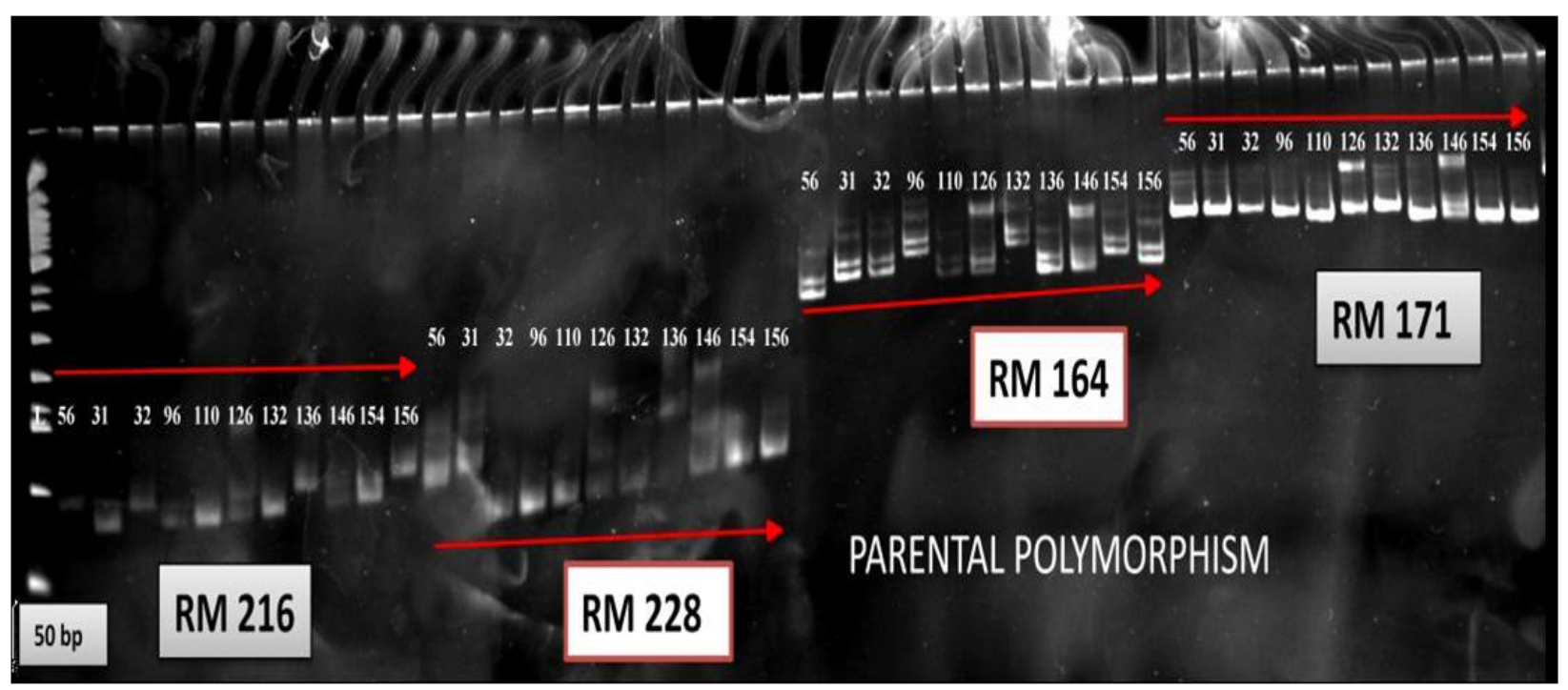

\begin{tabular}{|l|l|}
\hline $\mathbf{5 6}$ & IR79156A \\
\hline $\mathbf{3 1}$ & CRMS31A \\
\hline $\mathbf{3 2}$ & CRMS32A \\
\hline $\mathbf{9 6}$ & Swrna sub 1 \\
\hline $\mathbf{1 1 0}$ & NPT 38 \\
\hline $\mathbf{1 2 6}$ & R 1656-2816-9-3223-1 \\
\hline $\mathbf{1 3 2}$ & NPT-4 \\
\hline $\mathbf{1 3 6}$ & NPT-17 \\
\hline $\mathbf{1 4 6}$ & Jawaphool \\
\hline $\mathbf{1 5 4}$ & NPT 1 \\
\hline $\mathbf{1 5 6}$ & NPT 2 \\
\hline
\end{tabular}

Table.5 Gel image label description of Fig.2

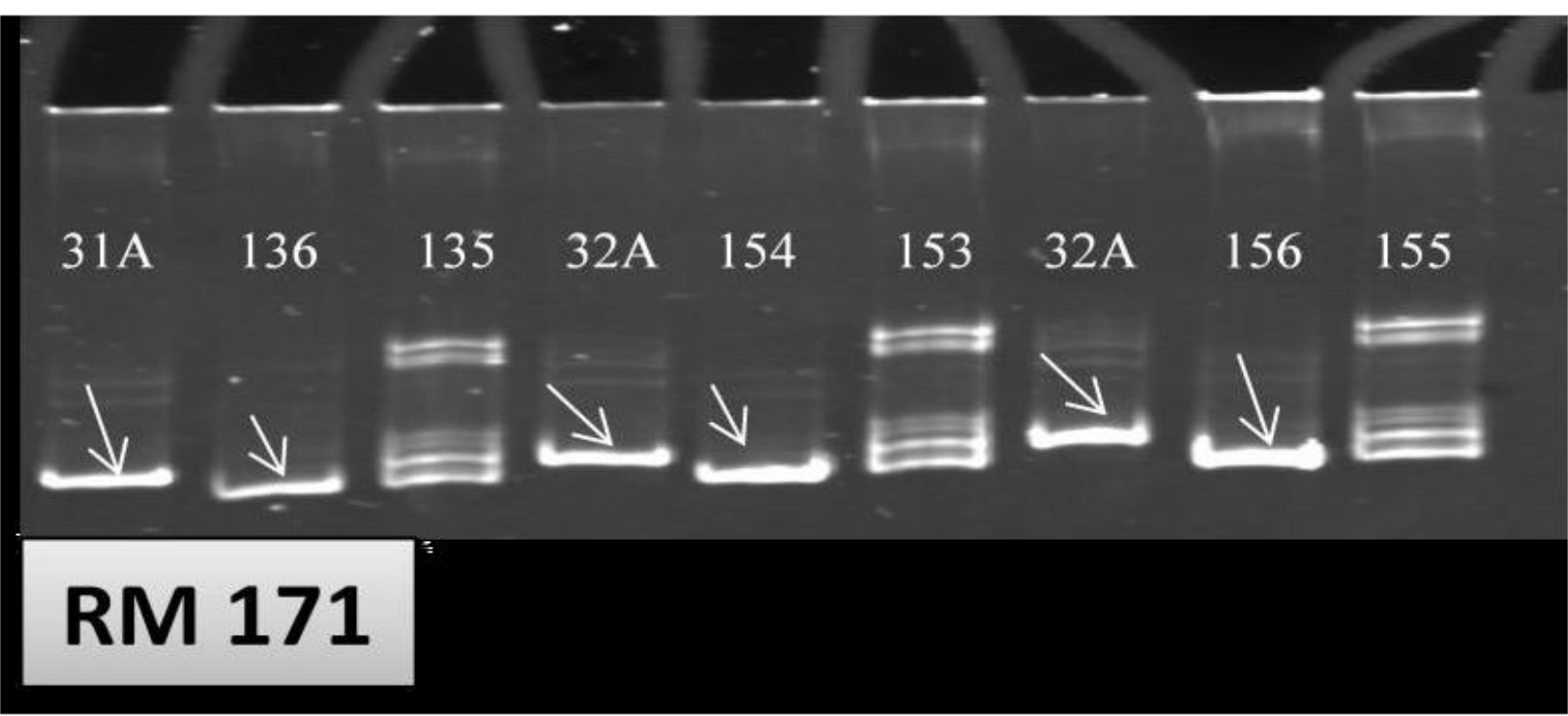




\begin{tabular}{|l|l|}
\hline 31A & CRMS 31A \\
\hline $\mathbf{1 3 6}$ & NPT-17 \\
\hline $\mathbf{1 3 5}$ & CRMS 31A $\times$ NPT-17 \\
\hline 32A & CRMS 32A \\
\hline $\mathbf{1 5 4}$ & NPT-1 \\
\hline $\mathbf{1 5 3}$ & CRMS 32A $\times$ NPT-1 \\
\hline $\mathbf{3 2 A}$ & CRMS 32A \\
\hline $\mathbf{1 5 6}$ & NPT-2 \\
\hline $\mathbf{1 5 5}$ & CRMS 32A $\times$ NPT-2 \\
\hline
\end{tabular}

Out of ten polymorphic markers, only two primers viz. RM 216 and RM171 have shown bands in both the parents (A lines and $\mathrm{R}$ lines), which indicating their absolute purity. Two primers were amplified as both alleles of their respective parents in RM 216 for a hybrid (IR 79156 A x Swarna Sub-1) hybrid and RM 171 for three hybrids viz. CRMS 31A/NPT-17, CRMS 32A/NPT 1 and CRMS 32A/NPT2, (Figs. 1 and 2). Identification and use of such hybrid specific markers can effectively reduce the cost and simplify the procedures of hybrid identification. Maintenance of hybrid seeds conformity in high level is essential for exploitation of hybrid vigor. Therefore, testing the hybrid seed purity is necessarily required before its release into the market. RM216 and RM171 markers for genetic purity test for three hybrids were recomended. Similar findings also reported by Yashitola et al., (2002), Rajendrakumar et al., (2007), Nandkumar et al., (2004) and Sundaram et al., (2008).

One DNA markers (RM 171) reported to be linked with restorer genes Rf4 of WA cytoplasm among eight tester lines. In present study RM171 showed efficiency in restorer identification whereas non-restorers also identified with higher selection accuracy in comparison with pollen and spikelet fertility (Table 3). These results are in close confirmation earlier reports Hashemi et al., (2013) found PCR based markers RM171 and exhibiting efficiency in restorer identification. In the present study heterozygous individual,
RM171 and RM 216 were successfully recognized as hybrid and was discriminated from its parental lines (with same alleles) and molecular screening with RM171 for fertility restoration can be a useful tool for identifying restorers from breeding lines of unknown restoration status with $100 \%$ efficiency without attempting and evaluating large number of test crosses. Thus use of molecular markers linked to $R f$ genes would save time and cost besides adding accuracy in identification of restorers. This marker are useful in marker assisted identification of $R f$ genes in recurrent back cross breeding program to develop near isogenic lines with multiple $R f$ genes towards the development of superior restorer lines.

\section{References}

Ahmadikhah A, Karlov GI, Nematzadeh GH, GhasemiBezdi K(2007) Inheritance of the fertility restoration and genotyping of rice lines at the restoring fertility $(R f)$ loci using molecular markers. Int $\mathbf{J}$ Plant Prod 1(1):13-21.

Alavi, M., Ahmadikhah, A., Kamkar, B. and Kalateh, M. 2009.Mapping Rf3 locus in rice by SSR and CAPS markers. Int. J. Genet. Mole. Biol., 1: 121-126.

Bazrkar L, Ali AJ, Babaeian NA, Ebadi AA, Allahgholipour $\mathrm{M}$, Kazemitavar $\mathrm{K}$, Nematzadeh G (2008) Tagging of four fertility restorer loci for wild abortive cytoplasmic male sterility system in rice (Oryza sativa L.) using microsatellite markers. Euphytica 164:669-677.

Doyle, J.J. and Doyle, J.L. 1987. A rapid DNA 
isolation procedure for small quantities of fresh leaf tissue. Phytochem Bull, 19: 1115.

Grishma Shah, Sasidharan, Sudeshna Chakraborty, N., Ruchi Trivedi, Rallapalli Ravikiran and Deepti Davla. 2012. Genetic diversity and molecular analysis for fertility restorer genes in Rice (Oryza sativa L.) for wild abortive (WA) cytoplasm using microsatellite markers. J. Agri. Tech., 8(1): 261-171.

Hashemi, S.H., Mohammad, S.A., Nematzadeh, G.A. and Arzani, A. 2009. Identification of rice hybrids using microsatellite and RAPD markers. African Journal of Biotechnology, 8(10): 2094-2101.

Nandakumar, N., Singh, A.K., Sharma, R.K., Mohapatra, T., Prabhu, K.V. and Zaman, F.U. 2004. Molecular fingerprinting of hybrids and assessment of genetic purity of hybrid seeds in rice using microsatellite markers. Euphytica.136(3): 257-264.

Neeraja, C. N., P. Balaji Suresh, N. Dharika, M. S. Ramesha, L. R. Vemireddy, R. M. Sundaram, and B. C. Viraktamath. 2009. Fine mapping of fertility restoration loci Rf3 and Rf4 for WA-CMS of rice. In 7th International Symposium on Rice Functional Genomics, 16-19 November 2009, Manila, Philippines, P. 5-15.

Nematzadeh GA, JuharAli A, Sattari M, Valizadeh A, Alinejad E, Nouri MZ (2006). Relation between different allogamic associated trait characteristics of the five newly developed cytoplasmic male sterile (CMS) lines in rice. Centr. Eur. Agric. J. 7: 49-56.

Revathi, P., PavaniMedoju, Arun Kumar Singh, R. M. Sundaram, SravanRaju, P., Senguttuvel, K., B. Kemparaju, A. S.
Hariprasad, M. S. Ramesha, C. N. Neeraja, N. Shobha Rani and B. C. Viraktamath. 2013. Efficiency of molecular markers in identifying fertility restoration trait of WACMS system in rice. Indian J. Genet., 73(1): 89-93.

Sheeba N. K., Viraktamath B. C., Sivaramakrishnan S., Gangashetti M. G., Pawan Khera and Sundaram R. M. 2009. Validation of molecular markers linked to fertility restorer gene(s) for WA-CMS lines of rice. Euphytica, 167: 217-227.

Sundaram R.M., Naveenkumar, B., Biradar, S.K., Balachandran, S.M., Mishra, B., Ilyasahmed, M., Viraktamath, B.C., Ramesha, M.S. and Sharma, N.P. 2008.dentification of informative SSR marker scapable of distinguishing hybrid rice parental lines and their utilization in seed purity assessment. Euphytica,163: 215-224.

Virmani SS, Mao CX, Hardy B (eds) (2003) Hybrid rice for food security, poverty alleviation, and environmental protection. Proceedings of the 4th international symposium on hybrid rice, Hanoi, Vietnam, 14-17 May 2002. Los Banos (Philippines): IRRI, 407 pp.

Virmani SS, Viraktamath BC, Casa CL, Toledo RS, Lopez MT, Manalo JO (1997) Hybrid rice breeding manual. IRRI, Philippines, $p$ 139.

Yashitola, J., Thirumurgan, T., Sundaram, R.M., Naseerullah, M.K., Ramesha, M.S., Sarma, N.P. and Santi, R.V. 2002.Assessment of purity of rice hybrid using microsatellite and STS markers. Crop Sci., 42: 13691373.

\section{How to cite this article:}

Alice Xalxo, Prabha R. Chaudhari, Deepak Sharma, Ritu R. Saxena, Satyapal Singh and Aashish Tiwari. 2017. Identification of Rice Hybrids and Restorer Line Using Microsatellite Markers. Int.J.Curr.Microbiol.App.Sci. 6(11): 3405-3411. doi: https://doi.org/10.20546/ijcmas.2017.611.399 